\title{
The Sensitizer 2,4-Dinitrofluorobenzene Activates Caspase- 3 and Induces Cell Death in a Skin Dendritic Cell Line
}

\author{
Maria Teresa Cruz, ${ }^{1,2}$ Carlos B. Duarte, ${ }^{2}$ Margarida Gonçalo, ${ }^{3}$ \\ Américo Figueiredo, ${ }^{3}$ Arsélio P. Carvalho, ${ }^{2}$ and Maria Celeste Lopes ${ }^{1,2}$ \\ ${ }^{1}$ Faculdade de Farmácia, Universidade de Coimbra, Coimbra, Portugal \\ ${ }^{2}$ Centro de Neurociências, Universidade de Coimbra, Coimbra, Portugal \\ ${ }^{3}$ Faculdade de Medicina (Serviço de Dermatologia), Hospital da Universidade de Coimbra, \\ Coimbra, Portugal
}

In this work, a dendritic cell line derived from mouse skin (FSDC) was used, as an in vitro experimental model, to evaluate the cytotoxic effect of two chemical sensitizers, a strong sensitizer (2,4-dinitrofluorobenzene, DNFB) and a weak sensitizer (2,4dichloronitrobenzene, DCNB). The results indicated that DNFB reduces the cellular metabolism of FSDC, as evaluated by the reduction of the tetrazolium salt, 3-(4,5-Dimethylthiazol-2-yl)-2,5diphenyl tetrazolium bromide (MTT). All the DNFB concentrations tested, ranging from $5.2 \mu \mathrm{M}$ to $26 \mu \mathrm{M}$, significantly inhibited the MTT reduction after 1 hour of cell exposure to the sensitizer. In contrast, incubation of FSDC with the weak sensitizer DCNB had no significant effect on the MTT reduction assay. When the cells were incubated with DNFB $(13 \mu \mathrm{M})$, for 3 and 6 hours, morphological changes characteristics of cell death by apoptosis were observed, as assessed by propidium iodide (PI) DNA staining and annexin-V externalization analysis. These results correlate well with an increase of caspase-3-like activity after FSDC exposure to DNFB $(13 \mu \mathrm{M})$ for 6 hours. Together, these results indicate that apoptotic death of skin dendritic cells occurs after exposure to the sensitizer DNFB, although necrotic cell death was also observed when the cells were incubated with high concentrations of DNFB $(26 \mu \mathrm{M})$, or after long periods of cell exposure to the chemical DNFB $(13 \mu \mathrm{M}$, for 6 hours).

Keywords Apoptosis, Caspase-3, Cell Death, DCNB, Dendritic Cells, DNFB

Received 26 April 2002; accepted 10 July 2002.

The authors thank Dr. G. Girolomoni (Laboratory of Immunology, Instituto Dermopatico dell'Immacolata, IRCCS, Rome, Italy) for the kind gift of the fetal skin-derived dendritic cell line (FSDC). This work was supported by Praxis/P/SAU/126/96.

Address correspondence to Maria Celeste Fernandes Lopes, Faculdade de Farmácia, Universidade de Coimbra, Rua do Norte, 3000-295 Coimbra Codex, Portugal. E-mail: mcflopes@imagem.ibili.uc.pt
Skin dendritic cells (DCs) are an epidermal population of cells characterized by their potent antigen-presenting capacity (Bancherau and Steinman 1998). They capture the antigen and leave the epidermal environment, migrating to the lymph nodes, where they contact with and activate naive T cells (Enk 1997). The process of DC migration is a tightly regulated event, dependent on allergens and epidermal cytokines, which induce the expression of cell surface markers essential for antigen presentation, such as the major histocompatibility complex class II molecules and costimulatory molecules (Bancherau and Steinman 1998).

Recent studies demonstrated that DCs are present in afferent lymph, but not in efferent lymph, suggesting that most of the migrating DCs die after their arrival to the lymph nodes (Banchereau and Steinman 1998). It was also reported that in tissue culture, fully differentiated or mature DCs undergo rapid apoptosis (Ludewig et al. 1995; Josien et al. 2000), unless they receive a survival signal from $T$ cells, which occurs after interaction of T cells with activated DCs (De Smedt et al. 1998). In addition, other recent evidences suggest that once DCs have interacted with $\mathrm{T}$ cells, they complete their differentiation process and die by apoptosis (Winzler et al. 1997; Matsue et al. 1999).

The aim of this work was to evaluate the effect of standard sensitizers on the metabolism and on the viability of a purified population of skin DCs. A dendritic cell line derived from fetal mouse skin (FSDC) was used as an in vitro experimental model exhibiting phenotypic and functional characteristics of immature DCs (Girolomoni et al. 1995). The effect of a strong contact sensitizer (2,4-dinitrofluorobenzene, DNFB) (Reiser and Schneeberger 1996) and a weak sensitizer (2,4dichloronitrobenzene, DCNB) (Basketter et al. 1996) was tested on the metabolism of FSDC, as determined by the reduction of 3-(4,5-Dimethylthiazol-2-yl)-2,5-diphenyl tetrazolium bromide 
(MTT), and on the decision of the cells to die by apoptosis or necrosis, as determined by propidium iodide (PI) DNA staining and annexin-V expression on cell surface (Rescigno et al. 2000). Since caspases, a group of intracellular cysteine proteases, participate in the initiation and execution phases of apoptotic cell death (Fadeel, Orrenius, and Zhivotovsky 2000), we studied the ability of DNFB to activate caspase-3.

\section{MATERIALS AND METHODS}

\section{Materials}

DNFB and DCNB were purchased from Sigma-Aldrich Química (Madrid, Spain). Fetal calf serum was obtained from Biochrom KG (Berlin, Germany) and trypsin was from Gibco (Paisley, UK). The protease inhibitor cocktail was purchased from Roche (Carnaxide, Portugal). Propidium iodide was obtained from Molecular Probes Europe (Leiden, The Netherlands). The caspase-3-like enzyme substrate, Ac-aspglu-val-asp-pNA (DEVD-pNA), was from Bachem (Bubendorf, Switzerland). All other reagents were either from Sigma Chemical Co. (St. Louis, MO, USA) or from Merck (Darmstadt, Germany).

\section{Cell Culture}

FSDC was kindly provided by Dr. G. Girolomoni (Girolomoni et al. 1995). The cells were cultured in Iscove's medium (Sigma) supplemented with $10 \%$ fetal calf serum, $1 \%$ glutamine, $100 \mu \mathrm{g} / \mathrm{ml}$ streptomycin, and $100 \mathrm{U} / \mathrm{ml}$ penicillin.

\section{MTT Assay}

Assessment of MTT reduction by metabolically active cells was carried out using a colorimetric assay (Mosman 1983). In this method, the optical density of the solution containing the formazan produced by metabolically active cells is measured spectrophotometrically. The cells $\left(0.2 \times 10^{6}\right.$ cells/well, cultured for 24 hours in 48 -well microplates) were incubated for $1,3,6$, and 12 hours with varying concentrations of two different chemical compounds, DNFB $(5.2,13$, and $26 \mu \mathrm{M})$ or DCNB $(5.2,13$, and $26 \mu \mathrm{M}$ ), or the corresponding vehicle, dimethyl sulfoxide. After removal of cell-free supernatants, $400 \mu \mathrm{l}$ of culture medium and $40 \mu \mathrm{l}$ of MTT solution $(5 \mathrm{mg} / \mathrm{ml}$ in phosphate-buffered saline [PBS]) were added to each well. The microplates were further incubated at $37^{\circ} \mathrm{C}$ for 1 hour, in a humidified atmosphere of $95 \%$ air $/ 5 \% \mathrm{CO}_{2}$. Supernatants were then discarded and $300 \mu \mathrm{l}$ of acidified isopropanol ( $0.04 \mathrm{~N} \mathrm{HCl}$ in isopropanol) were added to the cultures and mixed thoroughly to dissolve the dark blue crystals of formazan. Formazan quantification was performed using an automatic plate reader (SLT, Austria) at $570 \mathrm{~nm}$, with a reference wavelength of $620 \mathrm{~nm}$. The dimethyl sulfoxide concentration in the culture medium never exceeded $0.1 \%$, and the assay of cellular MTT reduction in the presence of this concentration of dimethyl sulfoxide revealed no toxic effect (data not shown).

\section{Detection of Apoptosis With Annexin-V Staining}

Cells grown on coverslips $\left(0.2 \times 10^{6}\right.$ cells/well, cultured during 24 hours in 48-well microplates) were incubated for 1 , 3 , or 6 hours with varying concentrations of DNFB (5.2 to $26 \mu \mathrm{M})$ in a final volume of $400 \mu \mathrm{l} /$ well. After removal of cell-free supernatants, the cells were washed twice with sodium medium (10 mM HEPES, $150 \mathrm{mM} \mathrm{NaCl}, 5 \mathrm{mM} \mathrm{KCl}, 1 \mathrm{mM}$ $\mathrm{MgCl}_{2}, 1.8 \mathrm{mM} \mathrm{CaCl}$, $\mathrm{pH}$ 7.4). They were subsequently stained, in the dark, for 5 minutes, with PI $(1 \mu \mathrm{g} / \mathrm{ml})$ and fluorescein isothiocyanate-labeled annexin- $\mathrm{V}(1 \mu \mathrm{g} / \mathrm{ml})$, dissolved in sodium medium. Fluorescence images were obtained using $488 \mathrm{~nm}$ (excitation) and $568 \mathrm{~nm}$ (emission) line of a krypton/ argon mixed gas laser, on a Bio-Rad MRC 600 fluorescent confocal microscope.

\section{Assaying of Caspase-3-Like Activity}

For caspase-3-like enzymatic activity analysis, the cells $(2 \times$ $10^{6}$ cells/well, cultured during 24 hours in 6-well microplates) were treated with culture medium (control), or with DNFB (5.2 to $26 \mu \mathrm{M}$ ), for 1,3 , and 6 hours. After treatment, the cells were washed twice with KPM $(50 \mathrm{mM} \mathrm{KCl}, 50 \mathrm{mM}$ PIPES, $10 \mathrm{mM}$ EGTA, $2 \mathrm{mM} \mathrm{MgCl} 2$, $\mathrm{pH}$ 7.0) and further washed once with KPM supplemented with $1 \mathrm{mM}$ dithiothreitol, $0.1 \mathrm{mM}$ phenylmethylsulfonylfluoride, and the protease inhibitor cocktail (complete KPM). Next, the cells were lysed with complete KPM containing $0.5 \%(v / v)$ Triton X-100, and crude extracts were prepared by two cycles of repeated freezing and thawing, followed by centrifugation at $18000 \times g$, for 10 minutes at $4^{\circ} \mathrm{C}$. Protein concentration in the supernatant was determined using the bicinchoninic acid solution (Sigma). Cells lysates (30 $\mu \mathrm{g}$ of protein) were incubated with $100 \mu \mathrm{l}$ of the reaction buffer composed of $25 \mathrm{mM}$ Hepes, pH 7.5, 0.1\% CHAPS $(w / v), 10 \mathrm{mM}$ dithiothreitol, $0.1 \mathrm{mM}$ phenylmethylsulfonylfluoride, and the protease inhibitor cocktail. The reaction was started by the addition of $100 \mu \mathrm{M}$ DEVD-pNA, followed by incubation at $37^{\circ} \mathrm{C}$ for 2 hours. Caspase-3-like activity was determined by monitoring the release of the cleaved substrate, every 15 minutes, using an automatic plate reader (SLT), at $405 \mathrm{~nm}$. The results are expressed as a percentage of the control rate of substrate cleavage.

\section{Data Analysis}

Results are presented as mean $\pm S E M$ of the indicated number of independent experiments. Mean values were compared using one-way analysis of variance (ANOVA) and the Bonferroni's multiple comparison test. The significance level was .05.

\section{RESULTS}

\section{The Contact Sensitizer DNFB Reduces the Metabolism of FSDC Cells}

As shown in Figure $1 A$, the strong contact sensitizer DNFB decreased the reduction of MTT by FSDC, with a rapid onset. 

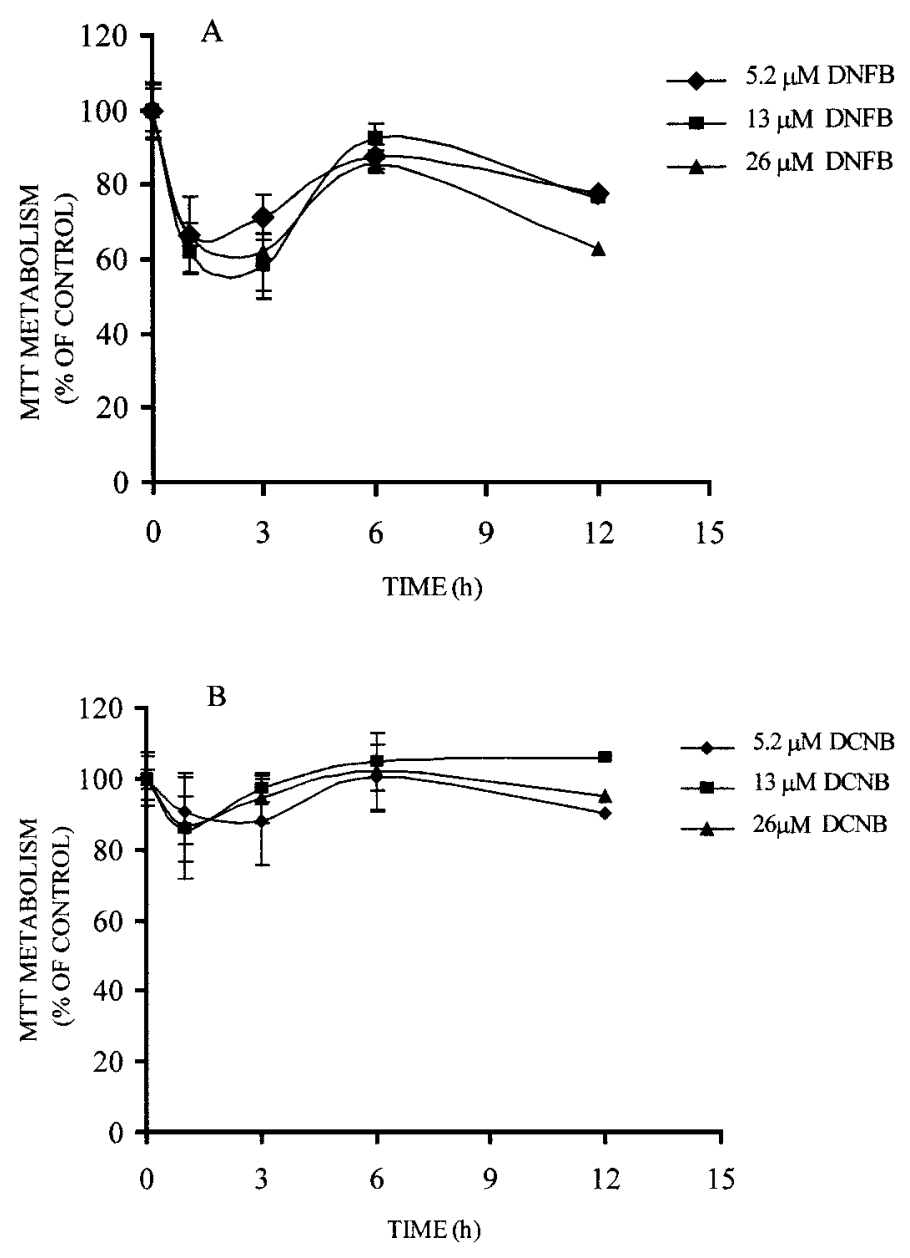

FIGURE 1

Effect of the exposure period to the chemicals DCNB and DNFB on the FSDC metabolism (MTT assay). The FSDC cells were exposed to different concentrations of DNFB $(A)$ or

$\operatorname{DCNB}(B)$, for $1,3,6$, and 12 hours. The MTT assay was performed as described in Materials and Methods. Results are expressed as a percentage of MTT metabolism by control cells maintained in culture medium. Each value represents the mean $\pm S E M$ from five experiments, performed in duplicate.

In contrast, incubation of FSDC with DCNB, at concentrations ranging from 5.2 to $26 \mu \mathrm{M}$, for as long as 12 hours, had no significant effect on MTT reduction (Figure 1B). All concentrations of DNFB tested $(5.2,13$, and $26 \mu \mathrm{M})$ inhibited MTT reduction by about $33 \%$ to $38 \%$ within the first hour of exposure (Figure 1A). A recovery period in MTT reduction was observed when the activity was measured in cells exposed to DNFB for 6 hours, but continuous exposure of FSDC to this sensitizer for 12 hours further evoked an inhibition of MTT reduction (Figure 1A). In the latter experimental conditions, and in comparison to the control value, the amount of blue formazan precipitates formed decreased to $77.3 \% \pm 3.2 \%(p<.001), 76.4 \% \pm$
$3.7 \%(p<.001)$, and $63.0 \% \pm 1.8 \%(p<.001)$ when the cells were incubated with $5.2,13$, or $26 \mu \mathrm{M}$ DNFB, respectively (Figure 1A).

\section{The Contact Sensitizer DNFB Induces Apoptotic Death of FSDC Cells}

We next examined the mode of cell death in FSDC incubated with DNFB. Cell death was measure with PI, a membrane impermeant dye that stains red the DNA of cells with a disrupted plasma membrane, and fluorescein isothiocyanatelabeled annexin- $\mathrm{V}$, which binds to the phosphatidylserine residues translocated to the external leaflet of the plasma membrane in cells undergoing apoptosis (Fadok et al. 1998; Rescigno et al. 2000). Viable cells with intact plasma membrane are therefore not stained with PI or with annexin-V. Apoptotic cells are not stained with PI, but because there is phosphatidylserine translocation to the external leaflet of the plasma membrane, they bind annexin-V. Necrotic cells are permeable to PI, which stains DNA, and are also permeable to annexin-V, which stains phosphatidylserine on the inner leaflet of the plasma membrane.

The results shown in Figure 2 were obtained by confocal microscopy and show that control FSDC cells do not display fluorescence after staining with fluorescein isothiocyanateconjugated annexin-V and PI (Figure $2 A$ ), and that apoptosis does not occur after cell exposure to $13 \mu \mathrm{M}$ DNFB for 1 hour (Figure 2B). However, after 3 to 6 hours of exposure to the sensitizer, cells in apoptotic stage were detected (Figure $2 C, D$ ). Incubation of the cells with the weak sensitizer compound DCNB, at $13 \mu \mathrm{M}$, for 3 hours, did not induce apoptosis (data not shown). When FSDC cells were exposed to higher concentrations of DNFB $(26 \mu \mathrm{M})$, for 1 hour (data not shown), or when they were exposed to $13 \mu \mathrm{M}$ DNFB, for 6 hours (Figure $2 D$ ), necrotic cells were also observed, with their nuclei labeled with PI, as indicated by arrows in Figure 2D. However, in Figure 2D, the large majority of the cells was stained by annexin- $\mathrm{V}$, but not by PI, indicating that cell death occurred mostly by apoptosis.

\section{DNFB Induces Caspase-3-Like Enzyme Activation in FSDC}

Because caspase-3 plays a key role in the execution phase of apoptotic cell death (Fadeel, Orrenius, and Zhivotovsky 2000), we next investigated caspase-3-like enzyme activation induced by DNFB, in FSDC, using the specific peptide substrate DEVDpNA. As shown in Figure 3, 6 hours exposure to $13 \mu \mathrm{M}$ DNFB induced caspase-3-like enzyme activation, from 100\% (control cells) to $173.23 \% \pm 13.45 \%$. However, DCNB or 1 and 3 hours exposure to DNFB did not induce caspase-3-like activity in FSDC (not shown).

\section{DISCUSSION}

The knowledge of the signaling events triggered in DCs by different sensitizers could help to modulate the skin 


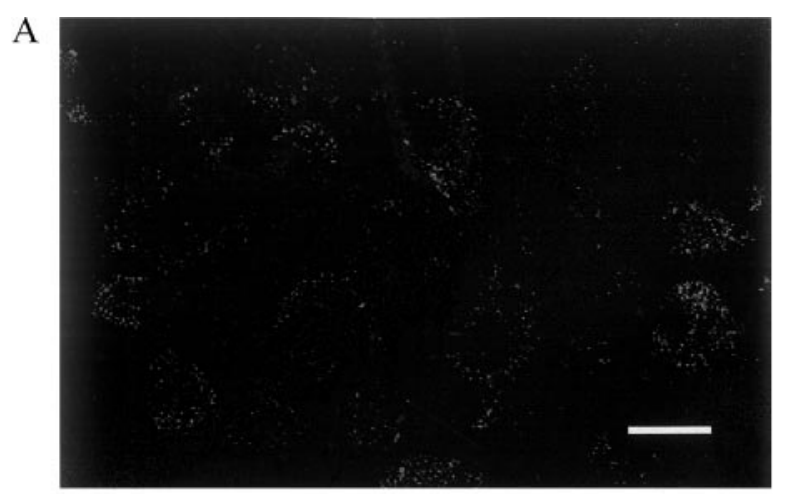

B

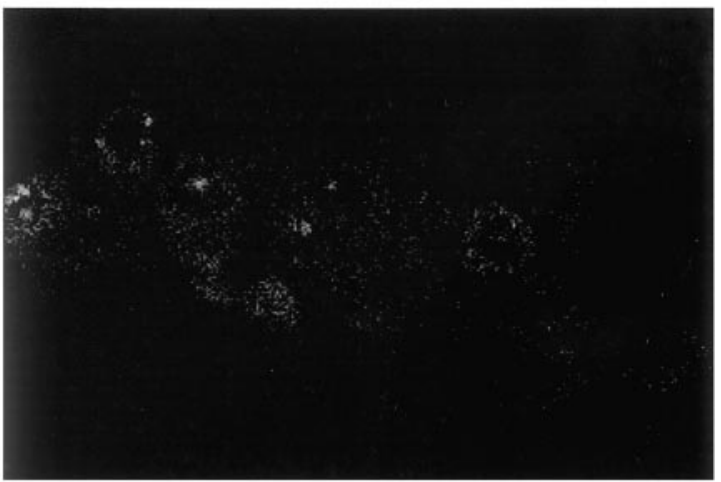

C

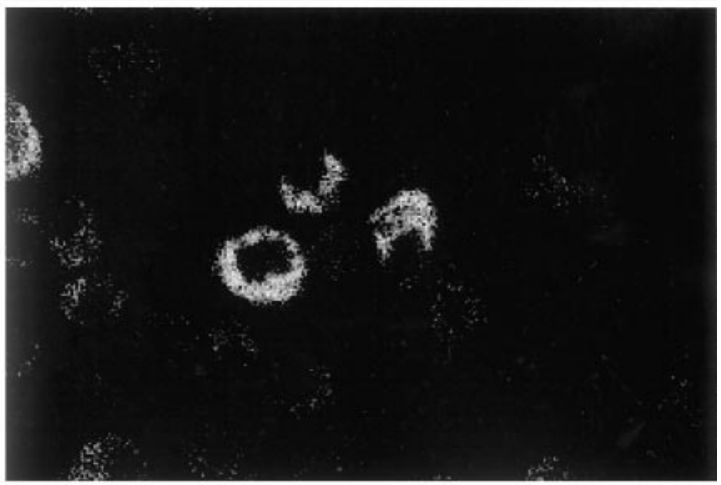

D

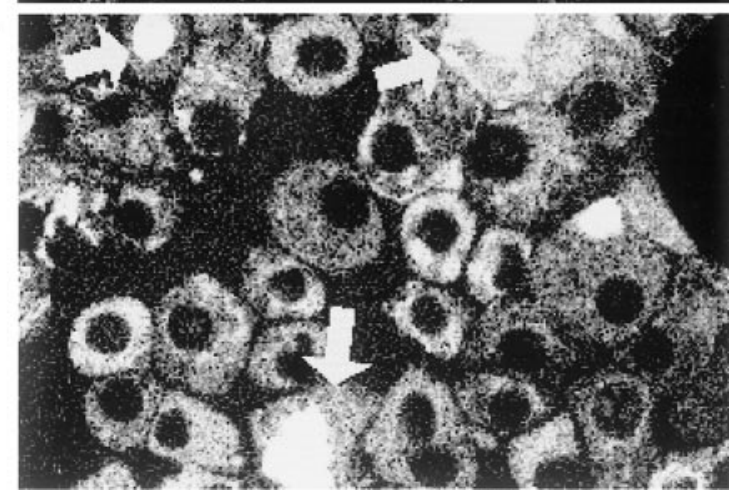

FIGURE 2

DNFB induces apoptosis in FSDC. FSDC cells were stained with propidium iodide $(1 \mu \mathrm{g} / \mathrm{ml})$ and fluorescein

isothiocyanate-annexin- $\mathrm{V}(1 \mu \mathrm{g} / \mathrm{ml})$, as described in Materials and Methods, after incubation with $13 \mu \mathrm{M}$ DNFB. (A) Control;

$(B)$ after $1,(C) 3$, or $(D) 6$ hours exposure to DNFB. The arrows indicate necrotic cells. Scale bars $=20 \mu \mathrm{m}$.

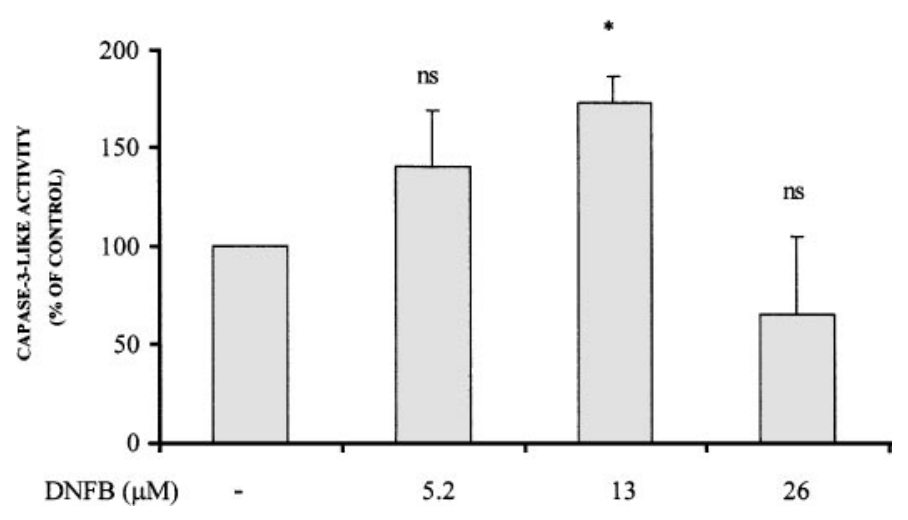

FIGURE 3

DNFB induces apoptosis in FSDC by activating the caspase-3.

FSDC cells were treated with culture medium (control), or were exposed to different concentrations of DNFB, for 6 hours.

Caspase-3-like activity was measured as described in

Materials and Methods. The results are expressed as a percentage of the control rate of substrate (DEVD-pNA) cleavage, measured at $405 \mathrm{~nm}$, every 15 minutes. Each value represents the mean $\pm S E M$ from five experiments, performed in duplicate $\left({ }^{*} p<.05 ;\right.$ ns, not significant).

inflammatory processes. In this work, the effects of two chemical sensitizers, a strong contact sensitizer (DNFB) and a weak sensitizer (DCNB), on the metabolism and on the viability of a DC line derived from fetal mouse skin (FSDC), which is representative of immature skin DC precursors (Girolomoni et al. 1995), were evaluated. The doses used in this work $(5.2,13$, and $26 \mu \mathrm{M})$ are in agreement with those used by other authors who performed in vitro studies in DCs (e.g., Manome, Aiba, and Tagami 1999). Our results show that only the strong sensitizer, DNFB, decreases the FSDC metabolism (Figure 1), activates caspase-3-like enzymes, and induces apoptosis (Figures 2 and 3).

Incubation of FSDC with DNFB, at $13 \mu \mathrm{M}$, rapidly decreased MTT reduction within 1 hour (Figure $1 A$ ), but staining with annexin- $\mathrm{V}$, which labels apoptotic cells, was detected only after 3 hours of exposure to the allergen (Figure 2C). Interestingly, the effect of DNFB on the metabolic activity (MTT assay) of FSDC showed a transient recovery phase after 6 hours exposure to the allergen (Figure 1A). This transient recovery of the MTT reduction during long-time exposure to DNFB suggests that this allergen causes a burst in the metabolic activity of the cells, which may result from DC activation by the sensitizer. In fact, DCs respond to sensitizing chemicals by producing cytokines and expressing costimulatory molecules (Aiba et al. 1997), and the level of phosphotyrosine increased in human DCs under stimulation with contact sensitizers (Kühn et al. 1998). The transient secondary increase of MTT reduction observed when the cells were continuously incubated with DNFB, for 6 hours, was followed by another phase of reduction of metabolic activity (Figure $1 A$ ), which is likely to correspond to cell death, mainly 
by apoptosis. This may occur due to incapacity of the activated FSDC to present the antigen to a naive $T$ cell in our experimental conditions. Accordingly, in monocytes-derived DCs, others sensitizers, such as $\mathrm{NiCl}_{2}$ and $\mathrm{CoCl}_{2}$, also induced apoptosis (Manome, Aiba, and Tagami 1999). In fact, in vivo, when mature DCs carrying the antigen are not stimulated through the CD40 molecule of the lymphocytes, they die by apoptosis (Thomas and Lipsky 1996).

Our results also show that DNFB caused death of a subpopulation of FSDC by necrosis. Necrotic FSDC cells were observed upon long periods incubation ( $>6$ hours) with $13 \mu \mathrm{M}$ DNFB (Figure 2D), or in the presence of higher concentrations of the allergen (data not shown). High concentrations of DNFB may cause energy failure and concomitant ATP depletion, precluding the activation of execution subroutines required for apoptotic cell death, leading to necrosis (Nicotera and Leist 1997). In contrast with the effects of DNFB, DCNB did not affect the ability of FSDC to reduce the MTT salt (Figure $1 B$ ) and was also without effect on annexin-V and PI staining (data not shown).

In contrast to necrotic cell death, apoptosis is a caspasedependent process of cell death, with associated classical morphological features, such as chromatin condensation and fragmentation, cell shrinkage, formation of 'apoptotic bodies,' and phosphatidylserine externalization, which permits the labeling of cells for phagocytosis (Cohen 1997). In recent years, a family of cysteine proteases, termed caspases, have been implicated in the process of cell destruction by apoptosis (Fadeel et al. 2000). Caspase- 3 is one of the key proteases of apoptosis, being responsible, at least in part, by the proteolytic cleavage of target proteins (Cohen 1997). Caspase-3 is widely distributed in mammalian cells, with high expression in cell lines of lymphocytic origin, suggesting that it may be an important mediator of apoptosis in the immune system (Cohen 1997). Here, we observed that $13 \mu \mathrm{M}$ DNFB induced caspase-3-like activation in FSDC, after 6 hours exposure of the cells to the chemical (Figure 3). These results correlate with the effect of DNFB on the annexin- $\mathrm{V}$ binding to FSDC under the same experimental conditions (Figure 2D). In contrast, incubation of FSDC with $26 \mu \mathrm{M}$ DNFB, for 6 hours, did not induce caspase-3-like activity (Figure 3), probably because the mode of cell death in this case was by necrosis.

Epidermal dendritic cells undergo apoptosis after ultraviolet B radiation (Takashima 1995; Kitajima et al. 1996), and recent studies suggest that cell death may facilitate antigen presentation and may be necessary for activation of the immune system (Chatergoon et al. 2000). Apoptotic cells (Rovere et al. 1998), and possibly necrotic cells (Sauter et al. 2000), were found to be sufficient to trigger DC maturation and the presentation of intracellular antigens from dying cells to lymphocytes.

In conclusion, our results suggest that DNFB induce cell death of dendritic cells, mainly by apoptosis. However, the mechanisms responsible for apoptotic death of dendritic cells upon exposure to the strong contact sensitizer and the consequences of this event in vivo remain to be determined.

\section{REFERENCES}

Aiba, S., A. Terunuma, H. Manome, and H. Tagami. 1997. Dendritic cells differently respond to haptens and irritants by their production of cytokines and expression of co-stimulatory molecules. Eur. J. Immunol. 27:3031-3038.

Banchereau, J., and R. M. Steinman. 1998. Dendritic cells and the control of immunity. Nature 392:245-252.

Basketter, D. A., E. W. Scholes, I. Fielding, R. J. Dearman, J. Hilton, and I. Kimber. 1996. Dichloronitrobenzene: A reappraisal of its skin sensitization potential. Contact Dermatitis 34:55-58.

Chattergoon, M. A., J. J. Kim, J.-S. Yang, T. M. Robinson, D. J. Lee, T. Dentchev, D. M. Wilson, V. Ayyavoo, and D. B. Weiner. 2000. Targeted antigen delivery to antigen-presenting cells including dendritic cells by engineered Fas-mediated apoptosis. Nat. Biotechnol. 18:974-979.

Cohen, G. M. 1997. Caspases: The executioners of apoptosis. Biochem. J. 326 : $1-16$.

De Smedt, T., B. Pajak, G. G. B. Klaus, R. J. Noelle, J. Urbain, O. Leo, and M. Moser. 1998. Cutting edge: Antigen-specific T lymphocytes regulate lipopolysaccharide-induced apoptosis of dendritic cells in vivo. J. Immunol. 161:4476-4479.

Enk, A. A. 1997. Allergic contact dermatitis: Understanding the immune response and potential for targeted therapy using cytokines. Mol. Med. Today 3:423-428.

Fadeel, B., S. Orrenius, and B. Zhivotovsky. 2000. The most unkindest cut of all: On the multiple roles of mammalian caspases. Leukemia 14:1514 1525

Fadok, V. A., D. L. Bratton, S. C. Frasch, M. L. Warner, and P. M. Henson. 1998. The role of phosphatidylserine in recognition of apoptotic cells by phagocytes. Cell Death Differ. 5:551-562.

Girolomoni, G., M. B. Lutz, S. Pastore, C. U. Abmann, A. Cavani, and P. Ricciardi-Castagnoli. 1995. Establishment of a cell line with features of early dendritic cell precursors from fetal mouse skin. Eur. J. Immunol. 25:2163-2169.

Josien, R., H.-L. Li, E. Ingulli, S. Sarma, B. R. Wong, M. Vologodskaia, R. M. Steinman, and Y. Choi. 2000. TRANCE, a tumor necrosis factor family member, enhances the longevity and adjuvant properties of dendritic cells in vivo. J. Exp. Med. 191:495-501.

Kitajima, T., K. Ariizumi, P. R. Bergstresser, and A. Takashima. 1996. Ultraviolet $B$ radiation sensitizes a murine epidermal dendritic cell line (XS52) to undergo apoptosis upon antigen presentation to T cells. J. Immunol. 157:3312-3316.

Kühn, U., P. Brand, J. Willemsen, H. Jonuleit, A. H. Enk, R. van BrandwijkPetershans, J. Saloga, J. Knop, and D. Becker. 1998. Induction of tyrosine phosphorylation in human MHC class II-positive antigen-presenting cells by stimulation with contact sensitizers. J. Immunol. 160:667-673.

Ludewig, B., D. Graf, H. R. Gelderblom, Y. Becker, R. A. Kroczek, and G. Pauli. 1995. Spontaneous apoptosis of dendritic cells is efficiently inhibited by TRAP (CD40-ligand) and TNF- $\alpha$, but strongly enhanced by interleukin-10. Eur. J. Immunol. 25:1943.

Manome, H., S. Aiba, and H. Tagami. 1999. Simple chemicals can induce maturation and apoptosis of dendritic cells. Immunology 98:481-490.

Matsue, H., D. Edelbaum, A. C. Hartmann, A. Morita, P. R. Bergstresser, H. Yagita, K. Okumura, and A. Takashima. 1999. Dendritic cells undergo rapid apoptosis in vitro during antigen-specific interaction with $\mathrm{CD} 4^{+} \mathrm{T}$ cells J. Immunol. 162:5287-5298.

Mosmann, T. 1983. Rapid colorimetric assay for cellular growth and survival: Application to proliferation and cytotoxicity assays. J. Immunol. Methods 65:55-63.

Nicotera, P., and M. Leist. 1997. Energy supply and the shape of death in neurons and lymphoid cells . Cell Death Differ. 4:435-442.

Reiser, H., and E. E. Schneeberger. 1996. Expression and function of B7-1 and B7-2 in hapten-induced contact sensitivity. Eur. J. Immunol. 26:880-885. 
Rescigno, M., V. Piguet, B. Valzasina, S. Lens, R. Zubler, L. French, V. Kindler, J. Tschopp, and P. Ricciardi-Castagnoli. 2000. Fas engagement induces the maturation of DCs, the release of IL- $1 \beta$, and the production of interferon $\gamma$ in the absence of IL-12 during DC-T cell cognate interaction: A new role for Fas ligand in inflammatory responses. J. Exp. Med. 192:1661-1668.

Rovere, P., C. Vallinoto, A. Bondanza, M. C. Crosti, M. Rescigno, P. RicciardiCastagnoli, C. Rugarli, and A. A. Manfredi. 1998. Cutting edge: Bystander apoptosis triggers dendritic cell maturation and antigen-presenting function. J. Immunol. 161:4467-4471.

Sauter, B., M. L. Albert, L. Francisco, M. Larsson, S. Somerson, and N. Bhardwaj. 2000. Consequences of cell death: Exposure to necrotic tumor cells, but not primary tissue cells or apoptotic cells, induces the maturation of immunostimulatory dendritic cells. J. Exp. Med. 191:423-433.

Takashima, A. 1995. UVB-dependent modulation of epidermal cytokine network: Roles in UVB-induced depletion of Langerhans cells and dendritic epidermal T cells. J. Dermatol. 22:876-887.

Thomas, R., and P. E. Lipsky. 1996. Dendritic cells: Origin and differentiation. Stem Cells 14:196-206.

Winzler, C., P. Rovere, M. Rescigno, F. Granucci, G. Penna, L. Adorini, V. S. Zimmermann, J. Davoust, and P. Ricciardi-Castagnoli. 1997. Maturation stages of mouse dendritic cells in growth factor-dependent long-term cultures. J. Exp. Med. 20:317-328. 
Copyright $\odot 2003$ EBSCO Publishing 